\title{
Cognitive versus stimulus-response theories of learning
}

\author{
Peter C. Holland \\ Johns Hopkins University, Baltimore, Maryland
}

\begin{abstract}
In his 1948 address to the Division of Theoretical-Experimental Psychology of the American Psychological Association, Kenneth W. Spence discussed six distinctions between cognitive and stimulus-response (S-R) theories of learning. In this article, I first review these six distinctions and then focus on two of them in the context of my own research. This research concerns the specification of stimulus-stimulus associations in associative learning and the characterization of the neural systems underlying those associations. In the course of describing Spence's views and my research, I hope to communicate some of the richness of Spence's S-R psychology and its currency within modern scientific analyses of behavior.
\end{abstract}

Spence (1948; 1950, p. 161) characterized cognitive theories of learning as those that "emphasized the formation and modification of cognitive patterns representative of the relationships in the environment." For the most part, within these theories, such as those of Koffka (1935), Kohler (1940), Lewin (1936), and Tolman (1932), learning was construed as part of a larger problem of perceptual organization and reorganization with experience. By contrast, stimulus-response (S-R) theories, such as those of Guthrie (1935), Hull (1943), Spence (1936), and Thorndike (1898), emphasized such constructs as habits and S-R bonds, which referred to hypothetical learning states or intervening variables. $\mathrm{S}-\mathrm{R}$ theories provided rules relating stimulus factors, such as reward magnitude, number, and timing, to the strengths of those intervening variables and rules relating those variables to empirical response measures. On the whole, Spence saw few points of disagreement between these two theoretical positions and attributed most of the dissension between the camps to misinterpretation of S-R theory by cognitive theorists. From my perspective, the tone conveyed in his article was that of a patient teacher pointing out the mistakes of well-intentioned but misguided students of cognition, but without sparing the somewhat-less-pervasive (in his eyes) mistakes of S-R theorists.

\section{Six Distinctions Between Cognitive and $\mathrm{S}-\mathrm{R}$ Theories}

Metaphors: Map control rooms versus telephone switchboards. Perhaps because spatial-learning tasks provided an important test arena for early cognitive and S-R psychologists, cognitive theories of learning became associated with the metaphor of "map control rooms," in which spatial representations and relations were acquired, computed, and exploited. By contrast, S-R theories became attached to the analogy of "telephone switchboards," by which stimulus inputs were, through learning, connected to new response outputs (Tolman, 1948). Spence (1950, p. 161) asserted that "no scientifically oriented person in psychology, however, would ever take such analogies, whether telephone switchboards or map control rooms, as serious attempts at theoretical representations of learning changes." For example, the meaning of Hull's habit construct was "given by the mathematical function relating it to the antecedent experimental variables," and thus, "any comparison of switchboards with map control rooms is entirely beside the point" (Spence, 1950, p. 163). More relevant was the question of whether learning in spatial tasks was more "map-like" or "habit-like"- that is, how much of the spatial information contained in those tasks was encoded in learning and could be used to guide performance later, when, for example, the usual paths were blocked or shortcuts opened (Tolman, Ritchie, \& Kalish, 1946a, 1946b). Interestingly, much of this debate was eventually distilled to the issue of place versus response, which could just as easily be phrased entirely in S-R terms as "approach cue X" versus "turn right."

Neurophysiological basis of learning: Brain fields or receptor-effector connections. Whereas cognitive theorists referred to reorganization of "electrical brain fields" and "neurophysiological trace systems," Hull (1943) related habit formation to the establishment of neural "receptor-effector" connections. Spence (1948, $1950)$ noted that these differences had little or no significance for learning theory because these neurophysiological models were nothing more than analogies and played no role in the deductions or inferences of either camp. Properties of "brain fields" were inferred from introspection, rather than from physiological investigation, and with few exceptions, knowledge or even speculation about

P. C. Holland, pch@jhu.edu 
the physiological basis of reflexes did not inform the construction of S-R theories. Indeed, Spence (1950, p. 164) stated that "picturing neurophysiological processes without specifying the hypothetical relations that tie them up with the experimental variables and the response measure is almost a complete waste of time so far as furthering our understanding of learning phenomena is concerned." In Section III of this article, I will relate examples of progress in relating brain and behavior that have been more useful in characterizing the nature of learning.

Stimulus-stimulus (S-S) or $\mathbf{S}-\mathbf{R}$ associations. Cognitive theorists of the time were clear that learning involved associations among, or reorganization of, sensoryperceptual processes. By contrast, Guthrie, Thorndike, Hull, and others posited that learning involved S-R associations, between stimuli and "muscle contraction and glandular secretion" (Guthrie, 1946, p. 7). Spence (1948, 1950) pointed out, however, that Hull's (1943) emphasis on S-R associations followed from his neurophysiological, rather than from his mathematical definition of habit. From Spence's perspective, there was nothing intrinsically S-R or S-S about habit, as defined within the Hullian system, although, like Hull, he clearly believed that most learning involved formation of associations between stimuli and responses:

I do not find it difficult to conceive of both types of organizations or associations being established in learning. Certainly simple types of perceptual learning would appear possibly to involve intersensory associations. I seriously doubt, however, whether learning is exclusively of this type, or even that the majority of it is. Indeed, . . . evidence would appear to support more strongly the S-R conception than the S-S. (Spence, 1950, pp. 164-165)

Most of this article (Section II) will be concerned with this issue.

Contents versus conditions of learning. Spence $(1948,1950)$ noted that cognitive theorists tended to emphasize the "intrinsic" properties of their constructs, whereas $\mathrm{S}-\mathrm{R}$ theorists tended to be concerned with the empirical relations among experimental variables that determine their constructs. In Rescorla's (1975) terminology, the cognitive theorists concentrated on the content of learning, whereas S-R theorists focused on the conditions under which learning occurred. Although castigating cognitive theorists for relying too much on introspection to make inferences about the contents of learning, Spence $(1948,1950)$ recognized that such contents could still be rigorously defined in terms of environmental variables, lauding Tolman's sign-gestalt psychology. Thus, he concluded that these concerns reflected "a very real difference between the two theoretical camps, but . . one of emphasis rather than of conflict" (Spence, 1950, p. 166).

Stimulus variables: Intrinsic versus extrinsic. At the time of Spence's (1950) writing, investigators from the cognitive tradition tended to examine the effects of variables that influenced the receipt of stimuli (e.g., orienting and attention) and perceptual organization (e.g., figure-ground relations, part-whole relations, belongingness, set). By contrast, most studies of behavior from the S-R tradition focused on temporal variables and those that related to motivation, such as reward magnitude and deprivation state. But Spence's (1950, p. 167) attitude was that "such differences of emphasis ... do not necessarily involve conflict" and noted that S-R theorists' preoccupation with time and motivation did not preclude an interest in stimulus reception and organizational variables. Indeed, in the past 25 years, a great deal of learning research emerging from the $\mathrm{S}-\mathrm{R}$ tradition has addressed the latter issues - for example, interests in orienting and attention (Holland, 1997; Mackintosh, 1975; Pearce \& Hall, 1980) and in perceptual organization (Cook, Riley, \& Brown, 1992; Rescorla, 1986).

Organism as active or passive processor of information. At the time of Spence's address (1948), there was considerable discussion about the "role of the organism" in information processing: whether animals "merely passively receive and react to all the stimuli which are physically present" (Tolman, 1948, p. 189) or actively process that information, selecting and assembling the elements of association prior to forming associations themselves. Again, Spence felt that cognitive theorists had misrepresented the $\mathrm{S}-\mathrm{R}$ position:

It is difficult to know for sure just what Tolman and others who have expressed this notion mean by this kind of statement. . . Much of the S-R theory is concerned with the classical conditioning situation in which the conditions of stimulation are extremely simple. No "active looking" for the cue ... or special receptor orientation is necessary. ... But even in the case of this simple learning situation the S-R learning theorist has not assumed that organisms passively receive and react to all stimuli that are physically present. (Spence, 1950, p. 168)

Thus, Spence set the stage for subsequent incorporation of variables that are now described as "attentional" into $\mathrm{S}-\mathrm{R}$ theory. For example, reinforcement contingencies may reasonably be expected to extend both to explicit attentional processing, such as eye movements and orienting behaviors (e.g., Siegel, 1967), and to the more implicit processing assumed by more recent learning theories, such as changes in learning rate parameters. All of these could influence the subsequent reception and use of particular stimuli in association formation later.

\section{Is Learning S-S or S-R?}

As Spence $(1948,1950)$ noted, there is nothing intrinsically S-S or S-R about a habit. For example, Figures 1A and 1B reproduce Spence's (1950) and Holland's (1990) diagrams distinguishing potential $\mathrm{S}-\mathrm{S}$ and $\mathrm{S}-\mathrm{R}$ associations in a simple Pavlovian conditioning experiment. If the second term of an association is late in the processing stream, we describe the association as $\mathrm{S}-\mathrm{R}$, and if it is early, we describe it as S-S. From this perspective, how late is late and how early is early define the question of whether an association or habit is S-R or S-S. 
A

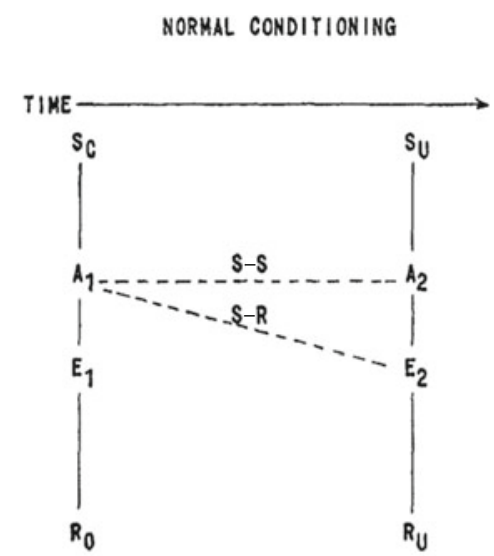

Fic. 3. Schematic representation of the classical conditioned response showing by means of the broken lines the two possible hypothetical associations $(S-S$ or $S-R)$.
B

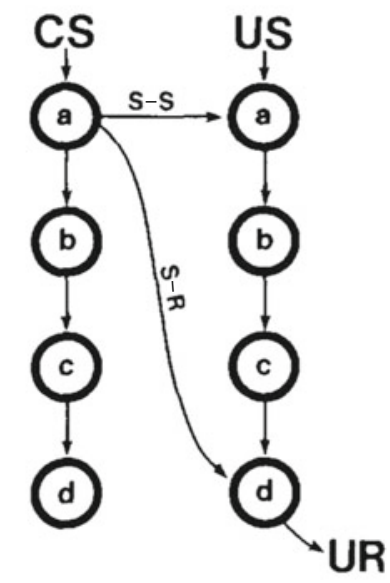

Figure 1. (A) Spence's (1950) diagram contrasting stimulus-stimulus (S-S) and stimulus-response $(S-R)$ associations. $S_{c}$ and $S_{u}$ refer to the conditioned and unconditioned stimuli, respectively; $A_{1}$ and $A_{2}$ refer to afferent processes produced by $S_{c}$ and $S_{u} ; E_{1}$ and $E_{2}$ refer to efferent processes produced by $A_{1}$ and $A_{2}$; and $R_{0}$ and $R_{u}$ refer to the orienting and unconditioned responses. (B) Holland's (1990) diagram contrasting $S-S$ and $S-R$ associations. CS, US, and UR refer to conditioned stimulus, unconditioned stimulus, and unconditioned response, respectively. The letters a-d refer to hypothetical stages of processing.

Because in the simplest case, such views suppose a linear chain of event processing from stimulus reception to motor output, it seems unlikely that dichotomous categorization of learned behaviors can be realistically made, within either psychological theories or neurophysiological theories, by pointing to differences in stimulus versus response processing or sensory versus motor brain regions. Nevertheless, there is likely to be considerable agreement that some events are "more stimulus" and others are "more response." Perhaps the earliest test arenas for asking the S-S or S-R question were those in which either stimulus or response aspects of the second, "reinforcer" event in an association event were minimized.

Responses without stimuli. Loucks (1935) examined learning when foreleg flexion in the presence of a buzzer was induced by electrical stimulation of the appropriate region of the motor cortex, rather than the usual foreleg shock unconditioned stimulus (US). In this procedure, the electrical stimulation was presumed to produce a response without preceding stimulus input. Thus, S-S learning should be impossible and S-R learning unaffected in this preparation. Indeed, Loucks found no evidence for acquisition of the leg flexion response, suggesting that contiguity of stimulus and response was insufficient for learning. Spence (1950) conceded the point but then noted that in a second experiment, Loucks found that if the buzzer-motor-cortex stimulation was also followed by food, leg flexion was acquired. Spence (1950) asserted that this pair of outcomes was easily interpretable within an S-R reward-based theory: Unlike leg shock, motor cortex stimulation produced a flexion response but no drive (pain) whose reduction could reinforce habit formation, whereas the addition of food added such a source of reward. Although others were to find successful limb flexion conditioning with motor cortex stimulation (e.g., Doty \& Giurgea, 1961), later experiments (e.g., Thomas, 1971; Wagner, Thomas, \& Norton, 1967) cast doubt on whether such studies revealed direct Pavlovian conditioning of leg flexion responses or the instrumental conditioning of responses that reduced the negative postural consequences of the sudden uncontrolled leg movements elicited by motor cortex stimulation. And apart from these concerns, one could easily question whether massive, unpatterned motor cortex stimulation would provide an appropriate basis for the plasticity needed for S-R learning at that point in the system. Notably, in some systems, such as eyelid conditioning, both the conditioned stimulus (CS) and the US can be replaced by direct stimulation of neural pathways (e.g., Steinmetz, Lavond, \& Thompson, 1989; Thompson, Thompson, Kim, Kripa, \& Shinkman, 1998; see Section III of this article).

Stimuli without responses. By the same logic, blocking responses to USs or choosing USs with minimal responses should substantially impair learning if learning is $\mathrm{S}-\mathrm{R}$ but should have little effect if learning is $\mathrm{S}-\mathrm{S}$. Early studies with peripheral blockade of responses during training typically revealed substantial responding after the blockade was removed (e.g., Finch, 1938). However, it is again easily argued that no one really expects S-R learning to be localized at the neuromuscular junction or sympathetic neuron. Such studies proved more useful in addressing claims that adventitious instrumental reinforcement 
of motor responses was responsible for the emergence of putatively Pavlovian conditioned responses (CRs).

A more fruitful line of research was that of sensory preconditioning, in which relatively neutral stimuli, such as lights and sounds, were paired. Although, typically, such CS1-CS2 pairings did not produce readily observable changes in behavior by themselves, subsequent pairing of one of them (CS2) with a more significant event, such as food or shock, typically produced learned responding to the other cue (CS1) as well (Figure 2A). Typically, CRs to the untrained CS1 cue were thought to be mediated by the chaining of two separately acquired associations at the time of performance. In the initial phase, S-S associations were formed between events that were mostly sensory in nature. Then, in the second phase, associations were formed between the CS2 and the US. Finally, when CS1 was presented in test, it would call up CS2, which in turn would elicit a CR (Figure 2B). Of course, imaginative $\mathrm{S}-\mathrm{R}$ theorists quickly proposed alternative, $\mathrm{S}-\mathrm{R}$ solutions to the sensory preconditioning problem. For example (Figure 2C), in the first phase, S-R associations could be formed between the CS1 and orienting responses (ORs) to CS2, and then associations between sensory feedback from those responses and the response to the US could be formed in the second phase. Finally, in test, S1 would elicit the conditioned OR originally elicited by CS2, and feedback from those conditioned ORs would, in turn, elicit the UR-like CR conditioned to those feedback stimuli in the second phase (Osgood, 1953, pp. 461-462). Because such responses were often not easily observed, these accounts were often difficult to support or refute. Nevertheless, hundreds of sensory preconditioning experiments have yielded evidence for learning in the absence of obvious responses (e.g., Thompson, 1972). I suspect Spence would have been content to describe these results as examples of sensory-sensory habits.

Both the S-S and the S-R accounts above assume that the performance of CRs to CS1 is mediated at the time of test presentations by chaining together separate associations previously established between CS1 and CS2 and between CS2 and the US. No direct associations are formed between CS1 and the US. An alternative account is that direct associations are formed between CS1 and the US in the second phase. By this "mediated learning" (Holland, 1981a) or "backward sensory preconditioning" (WardRobinson \& Hall, 1996) account, in the second phase, CS2 associatively activates a representation of CS1, which is then followed by the US. Thus, associations can be formed directly between CS1 and the US, which are then revealed in the final test of CS1 alone (Figure 2D). It is usually difficult to distinguish between these alternatives, although it is notable that in an early human sensory preconditioning experiment, Brogden (1947) distinguished between subjects who attributed their response to CS1 in test to its reminding them of CS2 and subjects who claimed that, in Phase 2, CS1 had actually been paired with the US. Subjects can be encouraged to use a "mediated learning" strategy by using conditioning parameters that discourage use of the CS1-CS2 associations required by the mediated performance account and, instead, encourage the use of

\section{Phase $1 \quad$ Phase 2 Test}

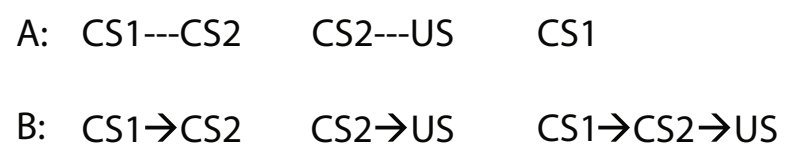
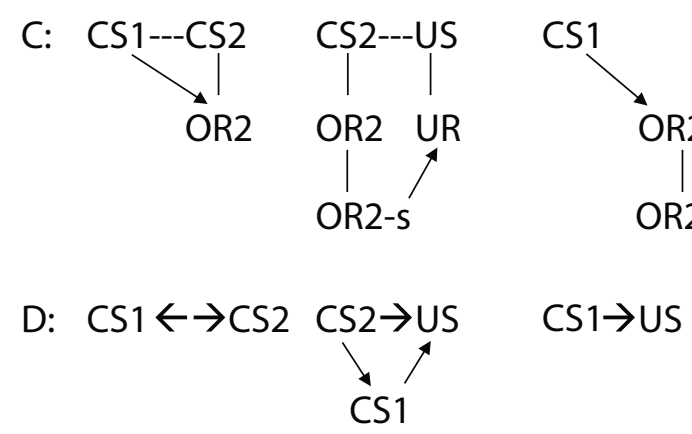

Figure 2. Procedures and outcomes of the sensory preconditioning experiment. (A) Experimental procedures. (B) Stimulusstimulus mediated performance account. (C) Stimulus-response mediated performance account. (D) Stimulus-stimulus mediated learning account. CS1, CS2, and US refer to two conditioned stimuli and the unconditioned stimulus. UR refers to the unconditioned response to the US. OR2 and OR2-s refer to the orienting response originally elicited by CS2 and to the stimulus feedback from OR2. Dashes (---) signify arranged relations; arrows $(\rightarrow)$ signify learned associations; double-headed arrows $(\leftarrow \rightarrow)$ signify bidirectional associations; lines $(-)$ signify unconditioned relations.

CS2-CS1 associations required by the mediated learning account. For example, Ward-Robinson and Hall presented the two neutral stimuli in the order CS2-CS1 in the first phase of a sensory preconditioning experiment and found substantial responding to CS1 in test.

Posttraining assessments of the nature of learning. In the experiments discussed above, the logic was to examine the consequences of altering the conditions of learning so that they would be conducive (or not) to either S-S or S-R learning. However, although such studies were useful for showing that learning could be S-S or $\mathrm{S}-\mathrm{R}$, they were not informative about whether learning in any typical conditioning procedure was $\mathrm{S}-\mathrm{S}$ or $\mathrm{S}-\mathrm{R}$. The use of posttraining tests of various sorts has often made it possible to collect such information.

Transfer tests. Perhaps the most common use of posttraining transfer tests was to determine whether rats in simple mazes learned spatial attributes of the maze environment or turn responses. For example, in Tolman's "sunburst" experiment (Tolman et al., 1946a), rats were trained in an apparatus in which they first ran straight down an alley, then had to make a left and two right turns before finding food on the right side of the room. In a transfer test, the rats were presented with alleys leading in a fanshaped array of angles from the start area. If the rats had learned "turn left" or "turn right" responses, they might be expected to choose the left-pointing $\left(0^{\circ}\right)$ or right-pointing $\left(180^{\circ}\right)$ alleys; if they had learned to "go straight then make turns," they would select the straight-ahead $\left(90^{\circ}\right)$ alley; but if they had learned the approximate location of the 
food in the room, they might select an alley that pointed to that location $\left(135^{\circ}\right)$. Although Tolman et al. (1946a) found considerable individual variation in the rats' choice behavior, the bulk of the data supported the assertion that the rats learned the approximate location of food (or that they integrated straight and right response vectors appropriately). A version of this experiment that has lasted longer follows T-maze training with a test in the maze when it has been rotated $180^{\circ}$ (Packard \& McGaugh, 1996; Poldrack \& Packard, 2003; Tolman et al., 1946b). Thus in the test, "response" and "place" strategies are placed in opposition. If the rat makes the same turn (e.g., right) as in training, response learning is identified, whereas if it approaches the same side of the room as in training, place learning is inferred.

Posttraining changes in reward. Another way of phrasing the $\mathrm{S}-\mathrm{R}$ versus $\mathrm{S}-\mathrm{S}$ question was whether rewards facilitate the formation of associations or participate in them. That is, does reward simply stamp in (Thorndike, 1898) or catalyze (Colwill \& Rescorla, 1986; Rescorla, 1988) S-R associations, or do animals form associations between stimuli and sensory and other properties of rewards? An initial approach to this question was to establish steady state performance with a particular reward and then substitute another reward. If reinforcers merely stamp in associations, no disruptions in performance would be expected (presuming the substituted reinforcer was of comparable value), whereas if animals anticipated particular rewards, aspects of performance might be sensitive to the change. Early delayed-response experiments showed that monkeys could maintain memory representations of particular food items over relatively long intervals. For example, working with Kohler, Tinklepaugh (1928) trained monkeys in a task in which, in view of the subject, the experimenter placed food under one cup, but not another, identical cup. After a delay in which the cups were screened from the monkey's view, the screen was removed, and the monkey was told to get the food. Several different foods were used, in different sessions. Normally, the monkey selected the correct cup and quickly consumed the food reward. However, if the experimenter hid a banana but then substituted lettuce under the cup while it was hidden from the monkey's view, the monkey examined but did not touch the lettuce, thoroughly investigated the cup, and on occasion shrieked at the experimenter. By contrast, on a subsequent trial in which lettuce was hidden and maintained under the cup, the monkey consumed the lettuce rapidly and without incident. Thus, from these reactions to the substituted reward, monkeys must have represented specific aspects of the reward in memory. Unfortunately, because the reward expectancy was produced by presentation of the reward itself, rather than by an associate of the reward, such experiments shed little light on whether reward properties are represented in associative learning. Closer to the mark was an experiment performed in Tolman's laboratory by Elliot (1928), in which different groups of rats were trained to run in a complex maze for either sunflower seeds or the preferred bran mash. After substantial training, in the bran group, the bran reward was replaced by the less-preferred sunflower seeds. Al- though the rats readily consumed the sunflower seeds with no signs of disturbance, performance on subsequent trials was considerably disrupted, so as to be worse than the performance of rats that had been trained with the sunflower seed reward from the start. This disruption suggested that the rats expected a particular reward. However, Elliot did not perform the analogous sunflower-to-bran substitution, and so the disruption may have reflected the effects of reduction in reward magnitude alone.

More recent experiments examined the effects of US substitution in Pavlovian conditioning in a more symmetrical manner. For example, Holland and Forbes (1982) found that either of two USs (differently flavored sucrose pellets) was better maintained in memory (assessed with a preparatory-releaser procedure; see, e.g., Terry \& Wagner, 1975 ) if they were preceded by an incongruent Pavlovian CS (i.e., for the other US) than by a congruent CS. Similarly, in my laboratory, Alexander Johnson (unpublished data) recently found that mice showed disruption of consumption of each of a pair of fluid USs (lecithin and sucrose) when each was accompanied by an auditory signal for the other fluid. Thus, at least some properties of the reinforcer seem to be coded by the CS after simple conditioning procedures.

Reinforcer revaluation. The post training reinforcer revaluation procedure (described formally by Rozeboom, 1958) has become the gold standard of assaying the presence or absence of S-S (Pavlovian) or R-S (instrumental) associations (Pickens \& Holland, 2004). Animals first receive Pavlovian or instrumental training with one or more reinforcers. Then the value of a reinforcer is altered in the absence of the cues or responses of training. Finally, responding is assessed in the absence of any of the reinforcers. Often, the level of response observed in test spontaneously changes to reflect changes in value of the reinforcer with which it had been previously paired. Major advantages of this paradigm include its utility after nearly any sort of training procedure and the availability of a wide range of methods for altering the value of rewards either upward ("inflation") or downward ("devaluation"). For example, motivational states relevant to the reinforcers can be induced chemically (e.g., increasing or decreasing sodium balance after training with salt solution rewards) or by altering exposure to them (e.g., selective satiation of one of two food rewards). Similarly, particular aspects of rewards may be altered associatively by pairing them with various agents that increase or decrease their attractiveness. Even nonassociative manipulations, such as simple exposure to the reinforcer itself, or weaker or stronger versions of the reinforcer, can be effective (e.g., Rescorla, 1973, 1974).

An early application of this method was a study by Zener and McCurdy (1939). Food-deprived dogs received pairings of two cues with different-flavored dog biscuits. Then the dogs were carefully sated on one of the flavors of dog biscuit. Finally, the dogs' reactions to each cue were noted. They responded much less energetically to the cue for the biscuit on which they were sated. Although, by present standards, the study was somewhat flawed because the biscuits continued to be presented in the test 
(and thus, the reduced responding may have reflected the lower reinforcement value of the sated biscuit, rather than a spontaneous adjustment of responding based on its altered value), these and other results encouraged Zener (1937) to describe conditioning as "a reorganization into some kind of functional whole of the perceptual systems corresponding to the conditioned and unconditioned stimuli; and in the functional relation of this organized system to the urge or tension system originally excited by the unconditioned stimulus" (p. 386) rather than the learning of $\mathrm{S}-\mathrm{R}$ associations.

A similar logic motivated early studies of discriminative maze or alley performance by Tolman (1933), Miller (1935), and Tolman and Gleitman (1949). Tolman (1933) initially trained rats in a two-choice discrimination box with two distinctive stimuli, black or white curtains. Passing through (say) the black curtains led to a food box, whereas passing through the white curtains led to a blind alley with no food. After substantial training on this task, the rats were placed directly in the food box and given an electric shock. Finally, the rats were returned to the start box and allowed to run. If the rats had truly learned the response-food-box associations or "sign-gestalt expectations," then even on the first trial they should fail to run. However, each rat "immediately dashed off gaily and just as usual through the whole discrimination apparatus and bang whack into the food compartment in which he had just been shocked" (Tolman, 1933, p. 250).

In a reply to Tolman (1933), Miller (1935) went one better by describing an S-R account for how rats could exhibit flexible behavior in such a situation and proceeded to demonstrate it. In his account, Miller made use of the concept of fractional anticipatory goal responses. Rats might make powerful goal responses (Rg; e.g., chewing), portions of which ( $\mathrm{rg}$ ) could be conditioned to alley cues that preceded the goal box itself. When a rat was subsequently placed in the goal box and shocked, leaping or freezing responses to the shock might be conditioned to stimulus feedback from the previous food-based goal responses (e.g., $\mathrm{Rg}-\mathrm{Sg} \rightarrow$ Rshock). Then, when the rat was placed back in the alley, performance of the conditioned rg would yield the feedback cue sg, which in turn would elicit a conditioned, fractional part of the response to shock, interfering with running. Miller suggested that all that would be needed to generate Tolman's (1933) anticipated data would be to give the goal boxes distinctive goal responses. He did this by using two rewards (food and water) and two distinctive goal boxes, one that required a climb and sharp right turn and one that required a straight entry followed by a sharp left turn. Unlike Tolman's (1933) apparatus, which required a simultaneous choice discrimination, Miller used a single alley with a single goal box but exposed the rats to the other goal box in the absence of the alley. When the rats were later placed directly into the entry of one of the goal boxes and shocked, the shock response would be conditioned to a particular $\mathrm{Sg}$ arising from the distinctive Rg in that box. If a rat was shocked in a goal box that was the same as the one that had always been found at the end of the alley, placing that rat back in the alley start box for test would elicit an rg whose sg feed- back was associated with the fractional shock response and, hence, would produce interference with running. By contrast, if the rat was shocked in the other goal box, the alley-elicited rg's sg feedback would not be associated with the shock response, and no such interference would be anticipated. Miller indeed found this outcome. Thus, Miller's S-R account not only explained such devaluation performance, but also suggested conditions under which it would and would not be observed.

Interestingly, in Tolman and Gleitman's (1949) classic T-maze study, in which Tolman finally succeeded in finding spontaneous devaluation performance, the two goal boxes were also constructed in such a way that they required distinctive goal responses (although Tolman and Gleitman instead emphasized the perceptual differences between the boxes). Finally, in one of the more bizarre twists on the logic of $\mathrm{rg}$-sg mediation of devaluation effects, using a variant of Miller's (1935) procedure, Fowler and Miller (1963) found that goal box shocks could either depress or enhance test performance, depending on whether the shocks were administered to the front or rear feet of the rats. If the shocks were administered to the front feet, the Rshock would be jumping back, but if they were administered to the back feet, the Rshock was leaping forward. When replaced in the alleys, the rats that had received goal shocks to the front feet jumped back, slowing their performance, but those that had received goal shocks to the back feet leaped forward, enhancing their performance. Thus, once again, the rg-sg mediation system not only provided an S-R account for "devaluation" effects, but also predicted the nature of the outcome on the basis of characterizations of the conditioned fractional anticipatory response.

The modern devaluation experiment. The modern devaluation experiment is associated with Rescorla's use of the procedure to examine the content of Pavlovian defensive (Rescorla, 1973, 1974) and appetitive (Holland \& Rescorla, 1975) conditioning and then, later, use of the procedure by Dickinson, Rescorla, and their colleagues to examine instrumental reward conditioning (e.g., Adams \& Dickinson, 1981; Balleine \& Dickinson, 1991; Colwill \& Rescorla, 1985b, 1986; Rescorla, 1987). In each of those studies, a modest effect of US devaluation after CS-US pairings was observed. For example, Holland and Rescorla (1975) paired a tone with food pellets and then devalued the food by either satiating the rats on those pellets or pairing them with high-speed rotation, inducing motion sickness. They found that rats that received such devaluation showed less responding than did those that had not received satiation or had received unpaired presentations of food and rotation. At the same time, rats that had received secondorder conditioning of the same tone showed no such effects of either devaluation treatment on second-order CRs, thus ruling out a variety of simple performance-based accounts for reduced responding after devaluation.

Results such as these have encouraged the authors of texts of learning and introductory psychology to assert that conditioning is predominantly S-S. But such a conclusion is not necessarily well supported. First, devaluation effects are typically small and, perhaps, confined to a 


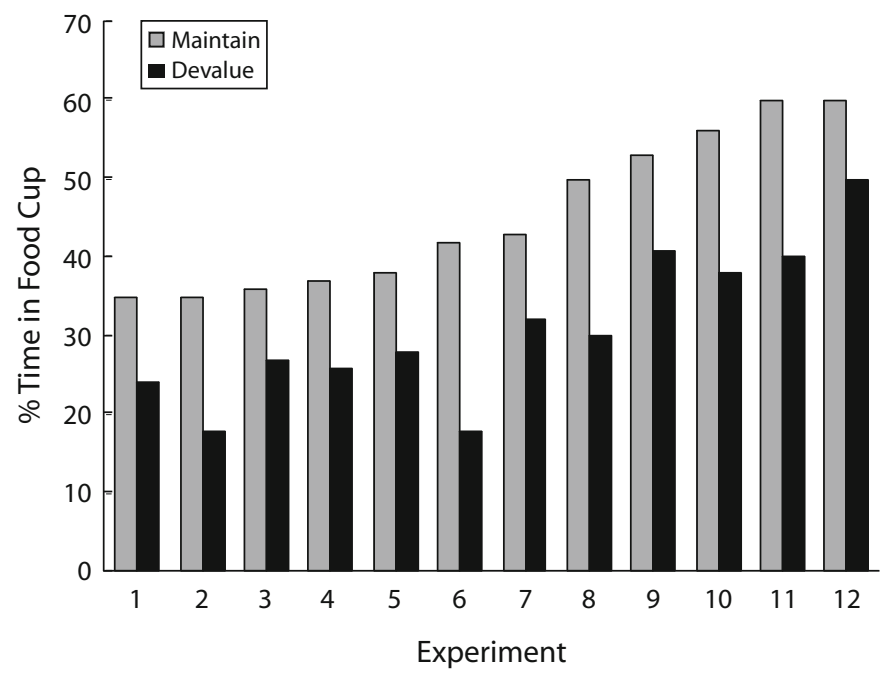

Figure 3. Test results of 12 devaluation experiments from my laboratory. In each experiment, an auditory or visual conditioned stimulus (CS) was first paired with food; then the food was either devalued by pairing it with lithium chloride $(\mathrm{LiCl})$ or maintained by presenting food and $\mathrm{LiCl}$ unpaired; and finally, the CS was presented alone in test.

limited range of training parameters. I have received many communications requesting "how-to" information from researchers who have failed to find devaluation effects. Although generally I have been able to set them on the road to success in obtaining the phenomenon, it is notable how small many devaluation effects are in absolute terms. For example, Figure 3 shows devaluation effects in the last dozen experiments published by members of my laboratory. Most of these studies were done in intact animals, although a few represent devaluation effects in rats with sham lesions of various brain regions known to be important for devaluation. The notable feature of these data is how small the differences between control and devaluation conditions are and how much responding remains after devaluation. In most cases, devaluation of the US itself was complete; that is, rats consumed nearly nothing of the food itself. Colwill and Rescorla (1990) have discussed this issue extensively in the context of instrumental devaluation, pointing to the importance of such variables as the similarity between patterns of US delivery in training and devaluation stages. Nevertheless, the residual is quite large in most circumstances (but see Colwill \& Rescorla, 1990; Kerfoot, Agarwal, Lee, \& Holland, 2007).

Second, the results of devaluation experiments can vary substantially as a function of the devaluation agent chosen. For example, Holland and Straub (1979) and Holland (1981b) examined the effects of devaluing food by satiation or by pairing it with lithium chloride $(\mathrm{LiCl})$ or highspeed rotation. Figure 4 shows consumption of the food and performance of anticipatory food cup entry responses to cues paired with food after devaluation by each of these three methods. In these studies, it was encouraging that the amount of reduction in consumption was positively correlated with the amount of reduction in food cup responding during the CS. At the same time, there are some conspicuous absences of such correlation as well. For example, Galarce, Crombag, and Holland (2007) trained rats with two auditory cues signaling two foods (sucrose and maltodextrin). One food was paired with $\mathrm{LiCl}$, whereas the other one was not. Finally, the rats were tested in the presence of the two tones. The unusual feature of this experiment was that, in different test sessions, either the averted or the nonaverted US was presented in the food cup during the devaluation test. Interestingly, the continuous presence of either of those foods in the food cups had little effect on responding to the CSs. Although not surprisingly, the rats spent more time in the food cup when it contained the nonaverted food than when it contained the averted food, the CS for the nonaverted food enhanced food cup responding more than the cue for the averted food regardless of which food was physically present. Thus, responding based on goal expectancy may occur despite clearly disconfirmatory goal evidence.

Another concern in devaluation experiments is the measure chosen to reflect outcome expectancy. First, some measures are more sensitive to devaluation than are others. Holland and Straub (1979) found that later-chain behaviors (such as contacting and picking up the pellet) showed more sensitivity to food devaluation by pairings with $\mathrm{LiCl}$ than did early-chain behaviors (approaching the food cup). Interestingly, some more indirect measures of learning, which are often thought to reflect conditioned incentive motivational properties, seem especially insensitive to devaluation. For example, Holland (2004) and Rescorla (1994) found no evidence that Pavlovian-instrumental transfer was affected by devaluation of the reinforcer. In Holland's (2004) study, after training with two CSs, two USs, and two instrumental responses, pairings of one US with $\mathrm{LiCl}$ reduced baseline levels of instrumental responding for that US, and reduced food cup responses to the CS 


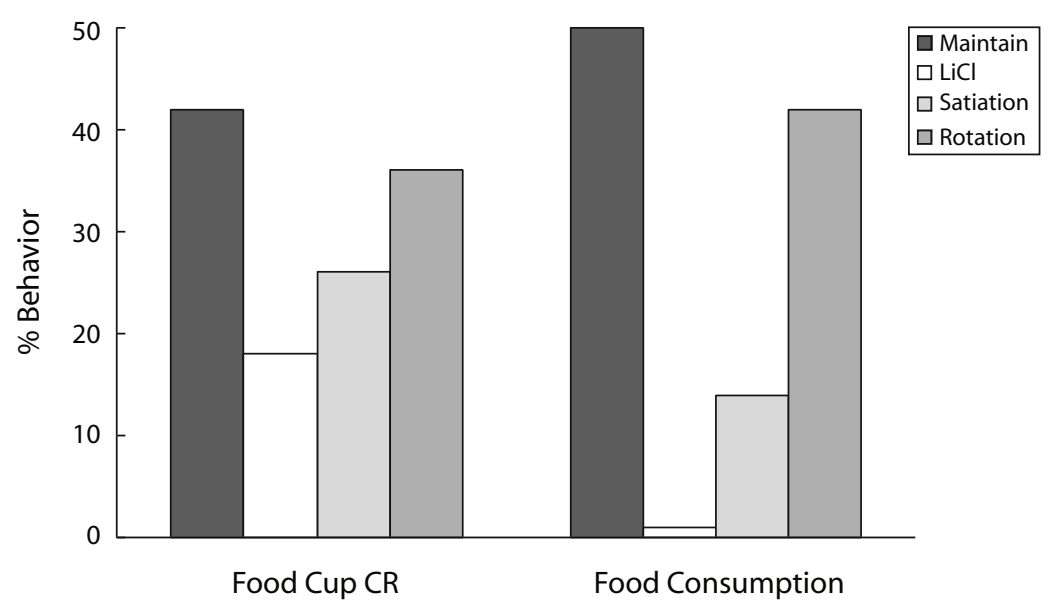

Figure 4. Left bars: Performance of food cup conditioned responses (CRs) to the conditioned stimulus (CS) alone in a test session after food was devalued by pairing it with lithium chloride ( $\mathrm{LiCl}$ ) or high-speed rotation, or by satiation on that food. Right bars: Number of food pellets consumed in 10 min after 50 food pellets were placed in the food cup in the experimental chambers. Responding in the maintain condition is a composite of responding to a test $\mathrm{CS}$ that was presented after unpaired presentations of food and $\mathrm{LiCl}$ or rotation, or in the absence of food satiation. Data are from Holland (1981b) and Holland and Straub (1979).

that predicted that US, but had no effect on the extent to which that CS enhanced instrumental responding that normally earned that US. Likewise, Parkinson, Roberts, Everitt, and di Ciano (2005) found that although, after repeated testing, US devaluation thoroughly eliminated responding evoked by a CS, that CS did not lose its ability to serve as a secondary or conditioned reinforcer.

Second, response measures and devaluation methods may interact. For example, although Holland and Straub (1979) found that devaluation of food by $\mathrm{LiCl}$ decreased food cup entry more than did devaluation by high-speed rotation, rearing to visual cues and startle responses to auditory cues were affected more by high-spend rotation than by food-LiCl pairings. By contrast, satiation reduced both classes of responding by an intermediate degree. Clearly "US value" is not unidimensional in its relation to behavior systems. Different behavioral responses may be mediated by different sensory properties of US representations, which in turn may be differentially sensitive to various devaluation methods. I will return to this issue briefly in Section III.

Third, appetitive and consummatory CRs may respond to reinforcer devaluation in quite different ways. Although, as is noted in Figure 2, food cup approach responses often show relatively little sensitivity to reinforcer devaluation, consummatory CRs, such as licking and a variety of so-called taste reactivity (TR; Berridge, 2000; Grill \& Norgren, 1978) measures thought to reflect hedonic or palatability aspects of rewards, are often are more completely eliminated. Using rats fitted with chronic intraoral cannulas, Kerfoot et al. (2007) paired a tone CS with the intraoral delivery of sucrose solution in a single session in two groups of rats and presented those events unpaired in other rats. Rats in the devalue group then were made ill by an $\mathrm{LiCl}$ injection after a single session of intraoral delivery of sucrose in the absence of tones, whereas rats in the maintain group received sucrose and $\mathrm{LiCl}$ on separate days. Control rats trained with tone and sucrose unpaired also received sucrose and $\mathrm{LiCl}$ either paired or unpaired in this phase. Finally, all the rats were tested with pairings of the tone with plain water infusions. The rats in the maintain group showed high levels of TR measures of positive (hedonic) affect on test trials (Figure 5A). Although these responses were especially evident in the presence of water, which provided a substrate for their performance, they also occurred during the tone alone, prior to the infusion of water on each trial. By contrast, the rats in the devalue group showed no more licking or positive TRs than did the control rats. Thus, devaluation was complete. In addition, these rats showed substantially more negative TRs, such as gaping and abbreviated licks, which are normally shown in response to averted flavors themselves, than did either the control or the maintain rats (Figure 5B). The occurrence of these negative TRs is especially important because devalue rats had never previously performed negative TRs to either the tone or the sucrose. At the time of tone-sucrose pairing and during sucrose-alone administration prior to $\mathrm{LiCl}$ injection, sucrose elicited only positive TRs, and sucrose was not presented again after the single $\mathrm{LiCl}$ injection. Thus, the display of negative TR responses by paired-devalue rats in test could not reflect S-R learning, even via the S-R (Osgood, 1953) or rg-sg (Miller, 1935) mediation mechanisms described earlier.

It is tempting to speculate from Kerfoot et al.'s (2007) results that learned consummatory or TR responses are especially sensitive to devaluation. However, a simpler possibility is that the intraoral delivery of the reinforcer and the use of that delivery method during both training and devaluation phases are more critical factors. Consistent with that possibility, Colwill and Rescorla (1990) found 

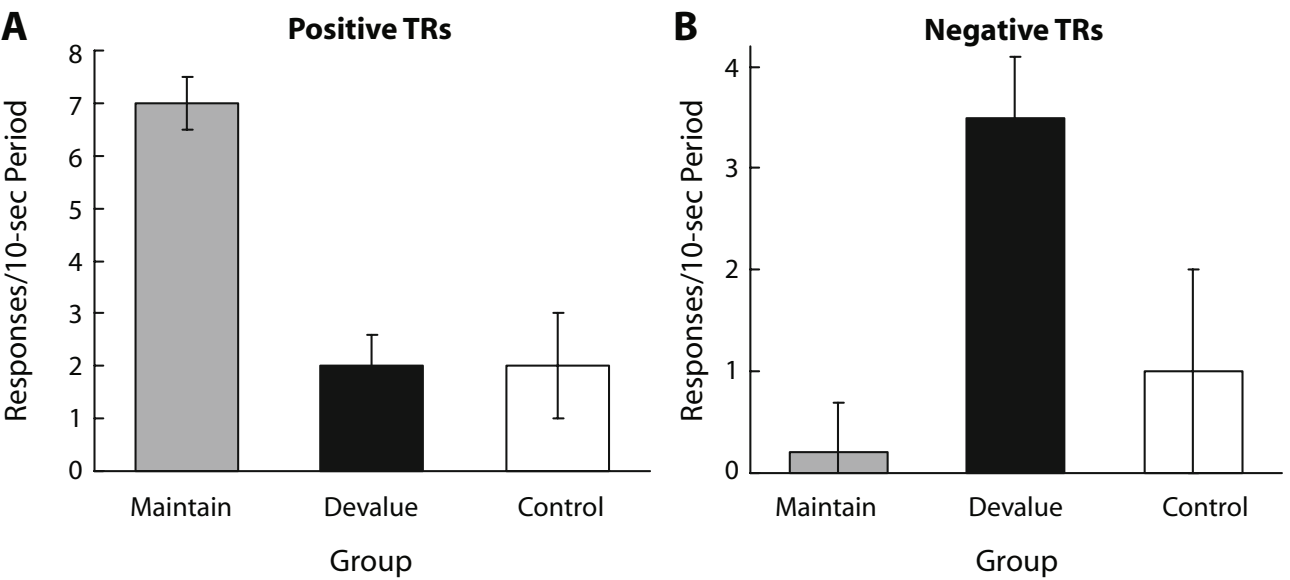

Figure 5. Positive (A) and negative (B) taste reactivity (TR) responses during test presentations of a tone conditioned stimulus (CS) and plain water in a devaluation test. Rats first received tone $\rightarrow$ sucrose pairings, followed by either sucrose-lithium-chloride $(\mathrm{LiCl})$ pairings (devalue) or unpaired presentations of those events (maintain). Control rats received tone and sucrose unpaired in training, followed by sucrose and LiCl either paired or unpaired. All fluids were delivered intraorally. Data are from Kerfoot, Agarwal, Lee, and Holland (2007).

nearly complete devaluation of operant leverpressing after training and devaluation with intraoral reinforcer delivery. More recently, Holland, Lasseter, and Agarwal (2008) examined consummatory and TR responses in devaluation experiments with either intraoral or conventional (to a recessed cup) delivery of sucrose reinforcers. The food cups were equipped with cameras to permit measuring TR responses in the cup condition, as well as in the intraoral delivery condition. Positive TR responses showed the same pattern regardless of sucrose administration method. With both intraoral and cup delivery methods, the rats in the devalue condition showed nearly complete loss of positive TRs after sucrose devaluation, relative to rats in the maintain condition, and only the rats in the devalue condition displayed negative TR responses (Figures 6A and 6C). At the same time, food cup entry showed only partial sensitivity to sucrose devaluation. In addition, in both delivery conditions, simple licking responses, characterized by Berridge (2000) as consummatory but nonhedonic, showed moderate but not complete sensitivity to devaluation. Thus, the results of Holland et al.'s study suggest that, regardless of reinforcer delivery method, evaluative TR responses are especially sensitive to devaluation, as compared with nonevaluative consummatory responses (simple licking) and (with conventional delivery) with appetitive responses (food cup entry).

A second purpose of Holland et al.'s (2008) study was to examine the effect of the amount of training on devaluation performance, with all of these measures. In the context of instrumental learning, it is often claimed (e.g., Adams, 1982; Kimble \& Perlmuter, 1970; but see Colwill \& Rescorla, 1985a; Colwill \& Triola, 2002; Holland, 2004) that learned responding becomes increasingly immune to reinforcer devaluation with extended training. Indeed, one of Tolman's (1933) alibis (his word) for not obtaining a devaluation effect was that his rats had been overtrained and had become "fixated" on running. We have never observed such an effect in Pavlovian conditioning; that is, Pavlovian CRs are at least as sensitive to food devaluation by pairings with $\mathrm{LiCl}$ after extended training as after minimal training (e.g., Holland, 1998, 2004, 2005). Nevertheless, we have frequently observed dramatic loss in the ability of a Pavlovian CS to participate in "mediated learning" as training proceeds.

Holland (1981a, 1990) found that mediated food aversion learning may be established when an associatively activated representation of food is paired with illness (see Holland \& Wheeler, in press, for a recent review). For example, in one experiment (Holland, 1981a), rats first received pairings of two auditory CSs with two food reinforcers that differed only in flavor (e.g., tone $\rightarrow$ wintergreen-flavored sucrose and noise $\rightarrow$ peppermintflavored sucrose), to give those CSs the ability to selectively activate representations of one or the other of those reinforcers. Next, presentations of one of the auditory CSs alone were paired with the injection of the toxin $\mathrm{LiCl}$, in the absence of any flavors. Subsequent consumption tests showed the establishment of a mild aversion to the food whose CS partner had been paired with illness, as if the CS's activation of a representation of food just prior to the induction of illness permitted the formation of foodillness associations. Later, Holland (1990, 1998, 2005) found that although CS-LiCl pairings established significant mediated food aversions after 16-24 CS-food pairings, rats trained with 40 or more CS-food pairings showed no evidence for such mediated food aversions. At the same time, other rats trained with as many as 160 CS-US pairings continued to display evidence for S-S tone-food learning, as indicated by reinforcer devaluation procedures. These results led Holland (1990, 1998, 2005 ) to suggest that early in training, CSs activate a wide range of processing usually activated by the US itself, including early-stage perceptual processing, but that, as training continues, access narrows to more limited sets 
A
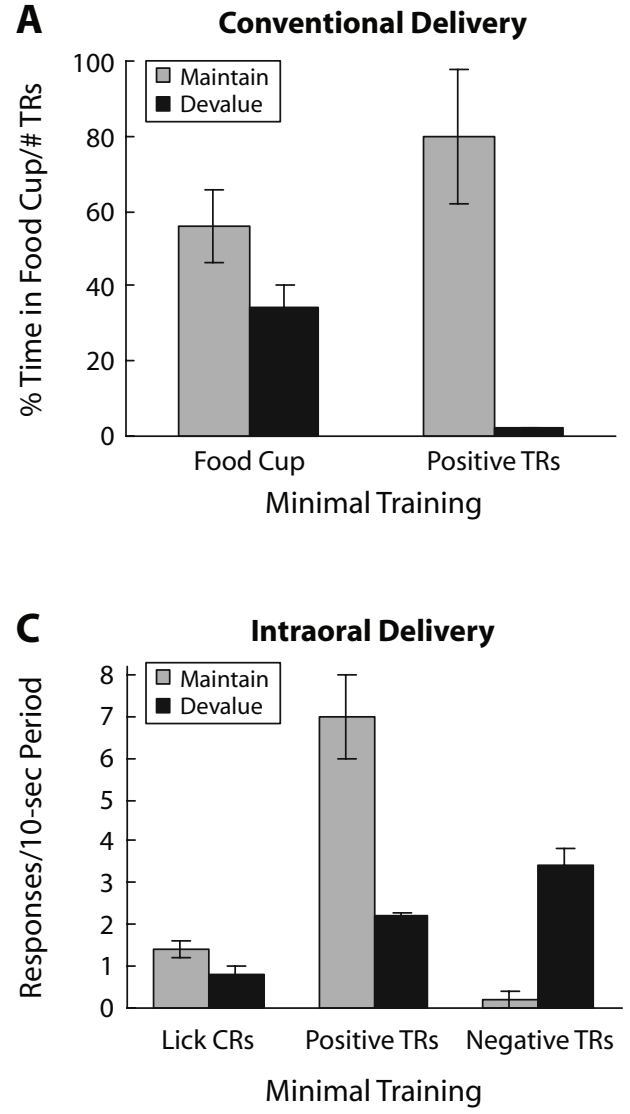
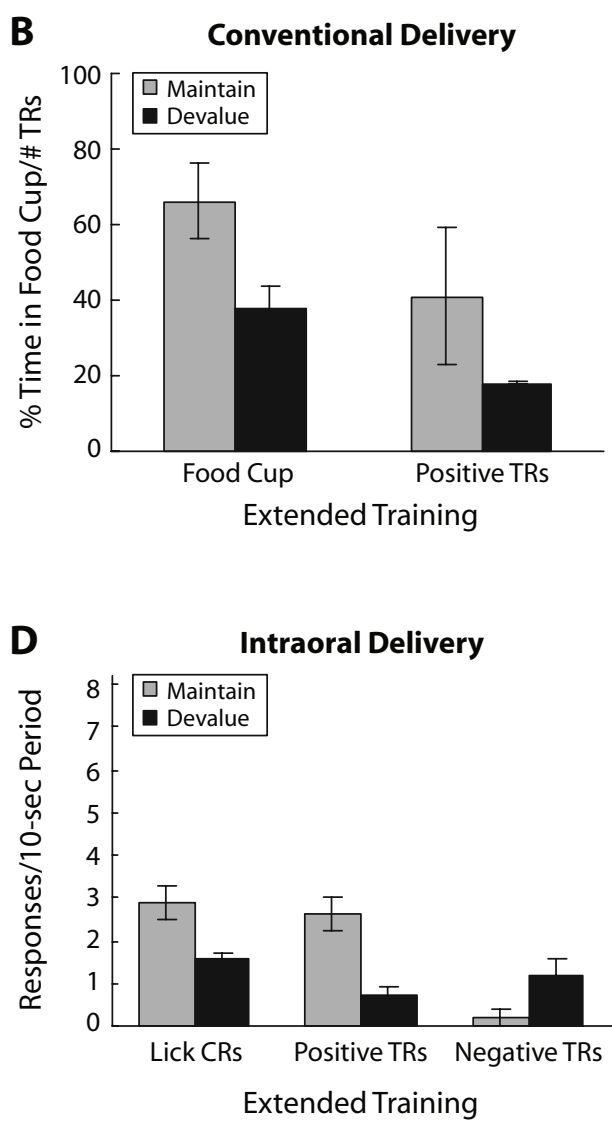

Figure 6. (A) Food cup and positive taste reactivity (TR) responding during test presentations on tone and plain water after minimal numbers of tone-sucrose pairings, followed by either pairings (devalue) of sucrose with lithium chloride ( $\mathrm{LiCl}$ ) or unpaired presentations of those events (maintain). (B) Same as in panel A, except after extensive tone-sucrose training. (C) Simple (nonevaluative) lick, positive TR, and negative TR responding during test presentations of tone and plain water, after minimal numbers of tone-sucrose pairings, followed by either pairings (devalue) of sucrose with $\mathrm{LiCl}$ or unpaired presentations of those events (maintain). (D) Same as in panel C, except after extensive tone-sucrose training. All fluids were delivered to a recessed food cup (panels A and B; Holland, Lasseter, \& Agarwal, 2008, Experiment 1) or intraorally (panels C and D; Holland et al., 2008, Experiment 2).

of processing systems. Thus, within this view, mediated flavor aversion learning was not observed later in training because the CS no longer activated perceptual processing of the absent flavor, which could enter into associations with illness.

The logic behind Holland et al.'s (2008) studies was that if the conditioning of TR responses to cues paired with sucrose reflects the cues' activation of perceptual processing of the absent sucrose and such activation occurs only early in training, only a minimally trained CS would control these positive evaluative responses, and a more extensively trained CS would not. In each of their experiments, Holland et al. trained each rat with two CSs, one paired with the sucrose US 16 times and the other paired with it 112 times. Figures 6A and 6C show the response to the minimally trained CS (described earlier), whereas Figures $6 \mathrm{~B}$ and $6 \mathrm{D}$ show the response to the extensively trained CS. As was anticipated, the display of conditioned TR responses was observed only after minimal training. At the same time, appetitive and nonevaluative consum- matory responses (simple licks) were sensitive to sucrose devaluation after either minimal or extensive training.

These data, like those from mediated learning studies, are consistent with the view (Holland, 1990) that early in training the CS activates perceptual processing normally activated by the food itself. Within this perspective, any function normally controlled by the taste of the US should be accessible by the CS. Thus, mediated learning of an aversion to that reinforcer would be expected if the CS was paired with $\mathrm{LiCl}$ injection, because the rat would experience illness after tasting the absent US. Similarly, that CS should control evaluative TR responses appropriate to that taste, as observed by Holland et al. (2008) and Kerfoot et al. (2007). Because the CS would activate preevaluative perceptual processing of the food US, the TR observed would be consistent with the current evaluation of the taste of that food and, thus, would be sensitive to posttraining changes in reinforcer value, as observed in those studies. By contrast, as training continues, the CS loses access to this low-level perceptual processing of the US and, instead, 
activates aspects of reinforcer processing that do not include perceptual experience itself or the ability to control evaluative responses appropriate to the current evaluation of that perceptual experience. These more conceptual aspects of the US nevertheless must include both sensory and some sort of motivational information, because reinforcer devaluation effects remain highly US specific even after the CSs lose their ability to control TR responses or mediate new taste aversion learning (Holland, 1998).

Clearly, there is more to the story than S-S versus S-R associations. The representations activated by CSs after minimal and extended training can be distinguished by their ability to participate in new (mediated) learning and by their ability to control appropriate evaluative TR responses. Nevertheless, even after extended training, CSs can activate reinforcer representations that include rich sensory information, which can subserve reinforcer devaluation effects. This distinction resembles one suggested by Konorski (1967; e.g., pp. 170-181), who distinguished between the associative activation of an "hallucination" and of an "image" by a CS. In the former case, the CS was thought to evoke activity of sensory "projective" units, which could resemble the activity of those units when they were activated by the US itself. By contrast, in the latter case, the CS activated only "gnostic" units, which coded information about the US but did not normally generate perceptual processing. Casually speaking, a hallucination includes sensory experience of an absent object, whereas one can imagine that object and its sensory properties without experiencing them.

\section{Can Neural Systems Analysis Help Us Understand the Contents of Learning?}

In Section I, I noted that Spence $(1948,1950)$ disparaged physiologizing, even Hull's, as more likely to be misleading than useful in characterizing mathematical and behavioral aspects of habit learning. However, the results of the devaluation tasks I've described imply that associative learning can engage a variety of levels of neural processing. Plasticity is not unique to any of the circles in Figure 1B. For example, studies of neural plasticity in eyelid conditioning (e.g., Medina, Nores, Ohyama, \& Mauk, 2000; Steinmetz et al., 1989; Thompson et al., 1998) have identified cerebellar sites of plasticity that are characterizable as being within "output" paths and, hence, more "S-R," as well as other sites earlier in the processing stream. A reasonable research program might imagine the circumstances under which cues come to control processing in different brain systems, which preferentially control different aspects of behavior. Understanding information flow in the brain may help us understand why, for example, some products of learning, such as the control of TR responses and the ability to support mediated learning, are related in their rapid bitonic acquisition functions, why others seem to maintain sensitivity to devaluation over extensive training, and why still others seem to lose such sensitivity over training.

A variety of neurobiological techniques have been harnessed to provide information relevant to understanding the contents of learning. The methods of brain stimula- tion have gone far beyond the crude stimulation of the motor cortex, as in Loucks's (1935) experiments. For example, in the neural systems analysis of eyelid conditioning, the replacement of real events such as CS and US (or both; e.g., Steinmetz et al., 1989) with brain stimulation has revealed events critical for eyelid conditioning. Similarly, patterned stimulation of the amygdala has helped elucidate the mechanisms of acquisition and extinction of fear conditioning (Vidal-Gonzalez, Vidal-Gonzalez, Rauch, \& Quirk, 2006).

Precise, pharmacologically selective lesions and reversible inactivations of various cell groups can selectivity alter rats' sensitivity to devaluation, without affecting other aspects of performance. For example, damage to components of circuitry, including the basolateral amygdala (BLA), the orbitofrontal cortex (OFC), subregions of the medial prefrontal cortex, and, in some situations, the mediodorsal thalamus, interfere with rats' Pavlovian devaluation performance without affecting the acquisition of food cup CRs or taste aversions (Gallagher, McMahan, \& Schoenbaum, 1999; Hatfield, Han, Conley, Gallagher, \& Holland, 1996; Maddux \& Holland, 2007; Pickens, 2008; Pickens et al., 2003). Furthermore, these studies indicate that different portions of that circuitry have specialized functions within the devaluation task. For example, for rats to display devaluation effects with single-reinforcer procedures, BLA function is needed during initial CS-food pairings, but not thereafter. That is, if rats acquire CS-food associations while BLA function is intact, subsequent lesions do not impair performance on this form of devaluation, as if BLA function is needed for rats to acquire $\mathrm{S}-\mathrm{S}$ rather than $\mathrm{S}-\mathrm{R}$ associations, but not to use previously established S-S associations to control behavior (Pickens et al., 2003). By contrast, OFC function appears to be critical for the expression, as well as the acquisition, of such associations in devaluation tasks. Lesions of the OFC disrupt devaluation performance (i.e., rats fail to spontaneously reduce responding to the CS after US devaluation) whether they are performed prior to CS-food, food aversion, or final test phases (Pickens, Saddoris, Gallagher, \& Holland, 2005; Pickens et al., 2003). Finally, involvement of these brain regions may vary with variations in task demands. For example, although when a single cue-reinforcer combination is used, BLA function is not required once cue-reinforcer associations are established, when two or more cues and reinforcers are used, BLA function must also be intact at the time of taste aversion training and/or devaluation testing (Johnson, Gallagher, \& Holland, 2007). Similarly, Pickens (2008) found that function of the mediodorsal thalamus was important for performance on a Pavlovian devaluation task only if that task required a strategy shift from a previous task.

The results of recent electrophysiological recording studies also suggest that conditioning procedures may establish a variety of types of associations, both within and across interconnected brain regions. For example, using an odor-cued discrimination task, Schoenbaum, Chiba, and Gallagher (1998) found neurons in the BLA and OFC that might be characterized as reflecting S-S and response-stimulus $(\mathrm{R}-\mathrm{S})$ associations. These neurons 
initially responded selectively to one of the two reinforcers used in the task, but over the course of training their activity came under the control of either a particular odor cue or a particular response. Later studies showed that the nature of neuronal coding of stimulus- or responseoutcome information in these two brain regions depended on communication between them (e.g., Saddoris, Gallagher, \& Schoenbaum, 2005; Schoenbaum, Setlow, Saddoris, \& Gallagher, 2003). Most recently, Furuyashiki, Holland, and Gallagher (2008) also contrasted the activity of OFC neurons that coded outcome information with those that coded response information. The latter neurons responded specifically to particular responses, but not to particular reinforcers. Although the latter neurons cannot be construed as a substrate for $\mathrm{S}-\mathrm{R}$ associations, because they increased their activity only after performance of the coded response, their existence shows that at least in some brain regions, individual neurons may code a variety of kinds of task information.

Finally, we have been using techniques of immediateearly gene expression to relate brain function to performance in simple devaluation (and other) tasks. Our intent is to relate variations in performance under different conditions to differences in brain systems engaged under those conditions. Postmortem tissue analysis can reveal detailed information about individual neurons that were active (Lee et al., 2005) or undergoing plastic change (Guzowski \& Worley, 2001; Petrovich, Holland, \& Gallagher, 2005) during fairly restricted time intervals, such as a particular behavioral test episode, before sacrifice. For example, after assessing TR responses to a minimally trained tone CS, in the absence of sucrose, Kerfoot et al. (2007; see Figure 5) sacrificed their rats to examine the expression of FOS, the protein product of the activitydependent immediate-early gene c-fos. They found learning- and devaluation-dependent FOS expression in a number of brain regions known from lesion experiments (just described) to be critical for learning that is sensitive to outcome devaluation (BLA and OFC; Holland \& Gallagher, 2004), in regions related to the display of TR responses (accumbens shell; Reynolds \& Berridge, 2002), and in regions related to processing of taste information (gustatory cortex; Kiefer \& Orr, 1992). These last observations are especially interesting from our earlier suggestion that conditioning may endow CSs with the ability to activate perceptual processing of absent USs. If, as a result of tone-sucrose pairings, the tone aroused the perception of sweetness, making the plain water taste sweet, rats in both the devalue and the maintain conditions might be expected to show enhanced FOS activity in the gustatory cortex, which they did. Furthermore, because rats in the maintain condition would respond to sweet with appetitive TR responses, the tone alone would also elicit those responses and FOS activity in a portion of the accumbens shell correlated with such responses. By contrast, because rats in the devalue condition would respond to sweet with aversive responses, the tone would provoke aversive responses and FOS in another subregion of accumbens shell correlated with aversive TR responses. All of these outcomes were observed. Given Holland et al.'s (2008) find- ings, it would be intriguing to determine whether a more extensively trained CS, which fails to elicit appetitive TR responses in training or evoke negative TR responses after devaluation, and which does not support mediated taste aversion learning, would also fail to induce FOS in the accumbens shell or the gustatory cortex.

Interestingly, although Kerfoot et al. (2007) found conditioning-dependent FOS expression in the central nucleus of the amygdala $(\mathrm{CeA})$, this expression was unaffected by devaluation condition (devalued or maintained). This observation is notable for three reasons. First, it suggests that associatively activated taste memories are not completely interchangeable with the tastes themselves. Taste and illness information converge in this region (Bernstein \& Koh, 2007; Yamamoto, 2007), and CeA is known to be important in many aspects of the learning and expression of taste aversions (Lamprecht \& Dudai, 2000; Yamamoto, 2007). However, if an associatively activated taste memory instigated these aspects of taste processing, we would have observed differential CeA activity in the maintain and devalue conditions. Second, lesions of CeA do not affect devaluation performance (Hatfield et al., 1996). Third, CeA function is critical for the acquisition of conditioned ORs, which in other circumstances Holland and Straub (1979) found to be relatively insensitive to devaluation by food- $\mathrm{LiCl}$ pairings. Taken together, these last two observations suggest converging evidence that relates differences in the sensitivity of conditioned ORs and food-related CRs to LiCl-based devaluation procedures (Holland \& Straub, 1979) to differences in brain circuitry subserving those learned responses. Differences in operating characteristics of those systems may determine the differential sensitivity of different behavioral systems to parameters of devaluation.

These neural systems studies of devaluation and related phenomena make it clear that questions of the contents of learning are complex. Even in apparently simple behavioral systems such as the eyeblink reflex, opportunities for plastic change abound in the neural systems that subserve them. The consequences of experimental manipulations of environmental stimuli for learning may vary considerably across these systems and their components. It has been increasingly difficult to distinguish between $\mathrm{S}-\mathrm{S}$ and S-R associations with any confidence on the basis of any single behavioral assay or aspect of neural processing. Characterization of multiple behavioral and neural consequences of variations in associative learning procedures should lead to richer, if perhaps less fathomable, descriptions of the nature of learning.

\section{Conclusions}

Within the context of $\mathrm{S}-\mathrm{S}$ versus $\mathrm{S}-\mathrm{R}$ associations in learning, the pendulum has swung decidedly to the cognitive side since Spence's day. There are now many demonstrations of encoding of detailed sensory aspects of reinforcers by CSs, from a range of behavioral paradigms, including sensory preconditioning, reinforcer devaluation, mediated learning, and others. Perhaps because of these many examples, the acquisition of S-R associations is seldom directly examined. The $\mathrm{S}-\mathrm{S}$ association 
has become the default, and absence of evidence for it is no longer taken as evidence for S-R associations, as it once was. For example, although devaluation effects are often small, the prevailing opinion seems to be that the residual responding after devaluation reflects inadequacy of the devaluation procedure, rather than S-R learning. This opinion may not be well-grounded. There are many examples of devaluation failure, and it is notable that few of the many brain lesions that impair devaluation performance produce general reductions in the measured CRs. Instead, animals with those lesions perform at normal predevaluation levels but fail to adjust their responding downward after devaluation. Thus, these lesions apparently alter what is learned from $\mathrm{S}-\mathrm{S}$ to $\mathrm{S}-\mathrm{R}$ associations without affecting the most obvious aspects of CR form. Furthermore, it is clear from neural systems studies that response-end plasticity occurs and that, through associative learning, neurons can come to code aspects of behavior, as well as of stimuli.

What of Spence's other five characterizations of " $\operatorname{cog}$ nitive versus stimulus-response theories of learning"? In terms of metaphors, both telephone switchboards and map control rooms have become anachronisms. As in Spence's day, most modern quantitative models of learning and behavior emphasize associative structures that could be equally construed as $\mathrm{S}-\mathrm{S}$ or $\mathrm{S}-\mathrm{R}$. Rich representations of tasks and outcomes in learning and flexibility in their use in performance are widely assumed to be the rule but are probably no better specified within formal models than the maps of yesteryear.

Spence was probably wise to ignore the neurophysiologizing of his day, because it had little basis in the study of the nervous system. Neurophysiological characterizations of learning are on much firmer ground today than they were in 1950 and are far more likely to be based on data than on speculation. Electrophysiological recoding methods can characterize neuronal coding of different kinds of information, and functional anatomical methods can be used to examine the bases of initially hypothetical brain networks underlying aspects of associative learning. Although many modern reductionist analyses of learning emphasize cellular and molecular changes underlying learning, these analyses are seldom taken as a substitute for behavioral analysis. Although I believe that the best way to further our understanding of behavior is to study behavior, neural analyses can often give us hints and clues about behavioral processes and organization. Perhaps just as important, the study of the neural basis of learning can connect the study of learning to a much broader scientific base and community.

In modern learning research, our choices of stimulus variables are much more eclectic than in Spence's day, with the same laboratories often investigating perceptual, motivational, and other variables and delving equally into determining the contents and conditions of learning. We are at least more receptive to the idea that the conditions and contents of learning are not independent and are more likely to pursue programs that examine, for example, the conditions that favor the formation of S-S or S-R learning than to ask simply, is learning $\mathrm{S}-\mathrm{S}$ or $\mathrm{S}-\mathrm{R}$ ?
In addressing the state of theorizing in the study of learning, Spence (1950, p. 171) lamented that

one almost gets the impression that the major goal is to prove the other conception wrong than to try to arrive at a more comprehensive interpretation of the phenomena. Psychologists interested and appreciative of the role of theory in the development of a scientific body of knowledge should resist such temptations ... elimination of all theorizing, would certainly not help to speed up the acquisition of a scientific body of knowledge about learning.

I think it is fair to say that the conflict between cognitive and $\mathrm{S}-\mathrm{R}$ theories of learning eventually went beyond this early competitive phase and stimulated great advances in our understanding of associative learning.

\section{AUTHOR NOTE}

In this article, I have borrowed heavily from Spence's (1950) original language but have provided marked quotations only for particularly lengthy or salient passages. Preparation of the manuscript was supported in part by NIH Grants MH53667 and MH65879. I thank the organizers of the September 2007 Iowa SpenceFest, Edward Wasserman, John Freeman, and, especially, Allan Wagner, whose excellent tutelage in the early 1970 s endured long enough for me to recall these classic studies so many years later. Correspondence concerning this article should be addressed to P. C. Holland, Department of Psychological and Brain Sciences, Johns Hopkins University, 3400 North Charles Street, Baltimore, MD 21218 (e-mail: pch@jhu.edu).

\section{REFERENCES}

ADAMs, C. D. (1982). Variations in the sensitivity of instrumental responding to reinforcer devaluation. Quarterly Journal of Experimental Psychology, 34B, 77-98.

AdAms, C. D., \& Dickinson, A. (1981). Instrumental responding following reinforcer devaluation. Quarterly Journal of Experimental Psychology, 33B, 109-121.

Balleine, B. W., \& Dickinson, A. (1991). Instrumental performance following reinforcer devaluation depends upon incentive learning. Quarterly Journal of Experimental Psychology, 40B, 279-296.

Bernstein, I., \& KoH, M. T. (2007). Molecular signaling during taste aversion learning. Chemical Senses, 32, 99-103.

BERRIDGE, K. C. (2000). Measuring hedonic impact in animals and infants: Microstructure of affective taste reactivity patterns. Neuroscience \& Biobehavioral Reviews, 24, 173-198.

BRogDEN, W. J. (1947). Sensory pre-conditioning of human subjects. Journal of Experimental Psychology, 37, 527-539.

Colwill, R. M., \& Rescorla, R. A. (1985a). Instrumental responding remains sensitive to reinforcer devaluation after extensive training. Journal of Experimental Psychology: Animal Behavior Processes, 11, 520-526.

Colwill, R. M., \& Rescorla, R. A. (1985b). Post-conditioning devaluation of a reinforcer affects instrumental responding. Journal of Experimental Psychology: Animal Behavior Processes, 11, 120-132.

Colwill, R. M., \& Rescorla, R. A. (1986). Associative structures in instrumental learning. In G. H. Bower (Ed.), The psychology of learning and motivation (Vol. 20, pp. 55-104). San Diego: Academic Press.

Colwill, R. M., \& Rescorla, R. A. (1990). Effect of reinforcer devaluation on discriminative control of instrumental behavior. Journal of Experimental Psychology: Animal Behavior Processes, 16, 40-47.

Colwill, R. M., \& Triola, S. M. (2002). Instrumental responding remains under the control of the consequent outcome after extended training. Behavioural Processes, 57, 51-64.

Cook, R. G., Riley, D. A., \& Brown, M. F. (1992). Spatial and configural factors in compound stimulus processing by pigeons. Animal Learning \& Behavior, 20, 41-55.

Doty, R. W., \& Giurgea, C. (1961). Conditioned reflexes established 
by coupling electrical excitation of two cortical areas. In J. F. Delafresnaye (Ed.), Brain mechanisms and learning (pp. 133-151). Oxford: Blackwell.

Elliot, M. H. (1928). The effect of change of reward on the maze performance of rats. University of California Publications in Psychology, 4, 19-30.

FINCH, G. (1938). Salivary conditioning in atropinized dogs. American Journal of Psychology, 124, 136-141.

Fowler, H., \& Miller, N. E. (1963). Facilitation and inhibition of runway performance by hind- and forepaw shock of various intensities. Journal of Comparative \& Physiological Psychology, 56, 801-805.

Furuyashiki, T., Holland, P. C., \& Gallagher, M. (2008). Rat orbitofrontal cortex separately encodes response and outcome information during performance of goal-directed behavior. Journal of Neuroscience, $\mathbf{2 8}, 5127-5138$.

Galarce, E. M., Crombag, H. S., \& Holland, P. C. (2007). Reinforcerspecificity of appetitive and consummatory behavior of rats after Pavlovian conditioning with food reinforcers. Physiology \& Behavior, 91, 95-105.

Gallagher, M., McMahan, R. W., \& Schoenbaum, G. (1999). Orbitofrontal cortex and representation of incentive value in associative learning. Journal of Neuroscience, 19, 6610-6614.

GriLl, H. J., \& Norgren, R. (1978). The taste reactivity test: I. Mimetic responses to gustatory stimuli in neurologically normal rats. Brain Research, 143, 263-279.

Guthrie, E. R. (1935). The psychology of learning. New York: Harper \& Row.

Guthrie, E. R. (1946). Psychological facts and psychological theories. Psychological Bulletin, 43, 1-20.

GuZOWSKI, J. F., \& WoRLEY, P. F. (2001). Cellular compartment analysis of temporal activity by fluorescent in situ hybidization (catFISH). In G. P. Taylor (Ed.), Current protocols in neuroscience (pp. 1-16). New York: Wiley.

Hatfield, T., Han, J.-S., Conley, M., Gallagher, M., \& Holland, P. C. (1996). Neurotoxic lesions of the basolateral, but not central, amygdala interfere with Pavlovian second order conditioning and reinforcer devaluation effects. Journal of Neuroscience, 16, 5256-5265.

Holland, P. C. (1981a). Acquisition of representation mediated conditioned food aversions. Learning \& Motivation, 12, 1-18.

Holland, P. C. (1981b). The effects of satiation after first- and secondorder appetitive conditioning. Pavlovian Journal of Biological Science, 16, 18-24.

Holland, P. C. (1990). Event representation in Pavlovian conditioning: Image and action. Cognition, 37, 105-131.

Holland, P. C. (1997). Brain mechanisms for changes in processing of conditioned stimuli in Pavlovian conditioning: Implications for behavior theory. Animal Learning \& Behavior, 25, 373-399.

Holland, P. C. (1998). Amount of training affects associativelyactivated event representation. Neuropharmacology, 37, 461-469.

Holland, P. C. (2004). Relations between Pavlovian-instrumental transfer and reinforcer devaluation. Journal of Experimental Psychology: Animal Behavior Processes, 30, 104-117.

Holland, P. C. (2005). Amount of training effects in representationmediated food aversion learning: No evidence of a role for associability changes. Learning \& Behavior, 33, 464-478.

Holland, P. C., \& Forbes, D. T. (1982). Control of conditional discrimination performance by CS-evoked event representations. Animal Learning \& Behavior, 10, 249-256.

Holland, P. C., \& Gallagher, M. (2004). Amygdala-frontal interactions and reward expectancy. Current Opinion in Neurobiology, 14, 148-155.

Holland, P. C., Lasseter, H., \& Agarwal, I. (2008). Amount of training and cue-evoked taste-reactivity responding in reinforcer devaluation. Journal of Experimental Psychology: Animal Behavior Processes, 34, 119-132.

Holland, P. C., \& Rescorla, R. A. (1975). The effect of two ways of devaluing the unconditioned stimulus after first- and second-order appetitive conditioning. Journal of Experimental Psychology: Animal Behavior Processes, 1, 355-363.

Holland, P. C., \& Straub, J. J. (1979). Differential effects of two ways of devaluing the unconditioned stimulus after Pavlovian appetitive conditioning. Journal of Experimental Psychology: Animal Behavior Processes, 5, 65-78.
Holland, P. C., \& WheEler, D. S. (in press). Representation-mediated food aversions. In S. Reilly \& T. Schachtman (Eds.), Conditioned taste aversion: Behavioral and neural processes. Oxford: Oxford University Press.

Hull, C. L. (1943). Principles of behavior. New York: AppletonCentury-Crofts.

Johnson, A. W., Gallagher, M., \& Holland, P. C. (2007, November). Examining the role of the basolateral amygdala in the expression of reinforcer devaluation. Poster presented at the 37th Annual Meeting of the Society for Neuroscience, San Diego.

Kerfoot, E. C., Agarwal, I., Lee, H. J., \& Holland, P. C. (2007). Control of appetitive and aversive taste-reactivity responses by an auditory conditioned stimulus in a devaluation task: A FOS and behavioral analysis. Learning \& Memory, 14, 581-589.

KIEFER, S. W., \& ORR, M. R. (1992). Taste avoidance, but not aversion, learning in rats lacking gustatory cortex. Behavioral Neuroscience, 106, 140-146.

Kimble, G. A., \& Perlmuter, L. C. (1970). The problem of volition Psychological Review, 77, 361-384.

KofFKA, K. (1935). The principles of Gestalt psychology. New York: Harcourt, Brace.

KoHLER, W. (1940). Dynamics in psychology. New York: Liveright.

KonORSKI, J. (1967). Integrative activity of the brain. Chicago: University of Chicago Press.

LAMPRECHT, R., \& DUDAI, Y. (2000). The amygdala in conditioned taste aversion: It's there but where? In J. P. Aggleton (Ed.), The amygdala: $A$ functional analysis (pp. 331-351). Oxford: Oxford University Press.

Lee, H. J., Groshek, F., Petrovich, G. D., Cantalini, J. P., GalLAGHER, M., \& Holland, P. C. (2005). Role of amygdalo-nigral circuitry in conditioning of a visual stimulus paired with food. Journal of Neuroscience, 25, 3881-3888.

Lewin, K. (1936). Principles of topological psychology. New York: McGraw-Hill.

LoucKs, R. B. (1935). The experimental delimination of neural structures essential for learning: The attempt to condition striped muscle responses to faradization of the sigmoid gyri. Journal of Psychology, 1, 5-44.

Mackintosh, N. J. (1975). A theory of attention: Variations in the associability of stimuli with reinforcement. Psychological Review, 82, 276-298

Maddux, J.-M., \& Holland, P. C. (2007, November). Lesions of the medial prefrontal cortex impair Pavlovian devaluation. Poster presented at the 37th Annual Meeting of the Society for Neuroscience, San Diego.

Medina, J. F., Nores, W. L., Ohyama, T., \& Mauk, M. D. (2000) Mechanisms of cerebellar learning suggested by eyelid conditioning. Current Opinion in Neurobiology, 10, 717-724.

MiLler, N. E. (1935). A reply to "Sign gestalt or conditioned reflex?" Psychological Review, 42, 280-292.

OsGOoD, C. E. (1953). Method and theory in experimental psychology. New York: Oxford University Press.

PaCKARD, M. G., \& McGaUgh, J. L. (1996). Inactivation of hippocampus or caudate nucleus with lidocaine differentially affects expression of place and response learning. Neurobiology of Learning \& Memory, 65, 65-72.

Parkinson, J. A., Roberts, A. C., Everitt, B. J., \& di Ciano, P. (2005). Acquisition of instrumental conditioned reinforcement is resistant to the devaluation of the unconditioned stimulus. Quarterly Journal of Experimental Psychology, 58B, 19-30.

Pearce, J. M., \& Hall, G. (1980). A model for Pavlovian learning: Variations in the effectiveness of conditioned but not of unconditioned stimuli. Psychological Review, 106, 532-552.

Petrovich, G. D., Holland, P. C., \& Gallagher, M. (2005). Amygdalar and prefrontal pathways to the lateral hypothalamus are activated by a learned cue that stimulates eating. Journal of Neuroscience, $\mathbf{2 5}$, 8295-8302.

Pickens, C. L. (2008). A limited role for mediodorsal thalamus in devaluation tasks. Behavioral Neuroscience, 122, 659-676.

Pickens, C. L., \& Holland, P. C. (2004). Conditioning and cognition Neuroscience \& Biobehavioral Reviews, 28, 651-661.

Pickens, C. L., Saddoris, M. P., Gallagher, M., \& Holland, P. C. (2005). Orbitofrontal lesions impair use of cue-outcome associations in a devaluation task. Behavioral Neuroscience, 119, 317-322. 
Pickens, C. L., Saddoris, M. P., Setlow, B., Gallagher, M., HolLAND, P. C., \& Schoenbaum, G. (2003). Different roles for orbitofrontal cortex and basolateral amygdala in a reinforcer devaluation task. Journal of Neuroscience, 23, 11078-11084.

Poldrack, R. A., \& PACKARD, M. G. (2003). Competition among multiple memory systems: Converging evidence from animal and human brain studies. Neuropsychologia, 41, 245-251.

RESCORLA, R. A. (1973). Effect of US habituation following conditioning. Journal of Comparative \& Physiological Psychology, 82, 137-143.

RESCORLA, R. A. (1974). Effect of inflation of the unconditioned stimulus value following conditioning. Journal of Comparative \& Physiological Psychology, 86, 101-106.

Rescorla, R. A. (1975). Pavlovian excitatory and inhibitory conditioning. In W. K. Estes (Ed.), Handbook of learning and cognitive processes (Vol. 2, pp. 7-35). Hillsdale, NJ: Erlbaum.

ResCorla, R. A. (1986). Two perceptual variables in within-event learning. Animal Learning \& Behavior, 14, 387-392.

Rescorla, R. A. (1987). A Pavlovian analysis of goal directed behavior. American Psychologist, 42, 119-129.

RESCORLA, R. A. (1988). Pavlovian conditioning: It's not what you think it is. American Psychologist, 43, 151-160.

RESCORLA, R. A. (1994). Transfer of instrumental control mediated by a devalued outcome. Animal Learning \& Behavior, 22, 27-33.

Reynolds, S. M., \& Berridge, K. C. (2002). Positive and negative motivation in nucleus accumbens shell: Bivalent rostrocaudal gradients for GABA-elicited eating, taste "liking"/“disliking" reactions, place preference/avoidance, and fear. Journal of Neuroscience, 22, 7308-7320.

Rozeвоom, W. W. (1958). "What is learned?" An empirical enigma. Psychological Review, 65, 22-33.

Saddoris, M. P., Gallagher, M., \& Schoenbaum, G. (2005). Rapid associative encoding in basolateral amygdala depends on connections with orbitofrontal cortex. Neuron, 46, 321-331.

Schoenbaum, G., Chiba, A. A., \& Gallagher, M. (1998). Orbitofrontal cortex and basolateral amygdala encode expected outcomes during learning. Nature Neuroscience, 1, 155-159.

Schoenbaum, G., Setlow, B., Saddoris, M. P., \& Gallagher, M. (2003). Encoding predicted outcome and acquired value in orbitofrontal cortex during cue sampling depends upon input from basolateral amygdala. Neuron, 39, 855-867.

SIEGEL, S. (1967). Overtraining and transfer processes. Journal of Comparative \& Physiological Psychology, 64, 471-477.

SPENCE, K. W. (1936). The nature of discrimination learning in animals. Psychological Review, 43, 427-449.

Spence, K. W. (1948, September). Cognitive versus $S-R$ theories of learning. Address to the Division of Theoretical-Experimental Psychology at the 56th Annual Meeting of the American Psychological Association, Boston

SPENCE, K. W. (1950). Cognitive versus stimulus-response theories of learning. Psychological Review, 57, 159-172.

Steinmetz, J. E., Lavond, D. G., \& Thompson, R. F. (1989). Classicalconditioning in rabbits using pontine nucleus stimulation as a conditioned-stimulus and inferior olive stimulation as anconditioned stimulus. Synapse, 3, 225-233.

Terry, W. S., \& Wagner, A. R. (1975). Short term memory for "surprising" versus "expected" unconditioned stimuli in Pavlovian con- ditioning. Journal of Experimental Psychology: Animal Behavior Processes, 1, 122-133.

Thomas, E. (1971). The role of postural adjustments in conditioning of dogs with electrical stimulation of the motor cortex as the unconditioned stimulus. Journal of Comparative \& Physiological Psychology, 76, 187-198.

Thompson, R. F. (1972). Sensory preconditioning. In R. F. Thompson \& J. S. Voss (Eds.), Topics in learning and performance (pp. 105-129). New York: Academic Press.

Thompson, R. F., Thompson, J. K., Kim, J. J., KripA, D. J., \& ShinkMAN, P. G. (1998). The nature of reinforcement in cerebellar learning. Neurobiology of Learning \& Memory, 70, 150-176.

ThORNDIKE, E. L. (1898). Animal intelligence: An experimental study of the associative processes in animals. Psychological Review Monograph Supplements, 2(4, Whole No. 8).

TinkLePAUGH, O. L. (1928). An experimental study of representative factors in monkeys. Journal of Comparative \& Physiological Psychology, 8, 197-236.

Tolman, E. C. (1932). Purposive behavior in animals and men. New York: Appleton Century.

Tolman, E. C. (1933). Sign-gestalt or conditioned reflex. Psychological Review, 40, 246-255.

Tolman, E. C. (1948). Cognitive maps in rats and men. Psychological Review, 55, 189-208.

Tolman, E. C., \& Gleitman, H. (1949). Studies in learning and motivation: I. Equal reinforcements in both end-boxes, followed by shock in one end-box. Journal of Experimental Psychology, 39, 810-819.

Tolman, E. C., Ritchie, B. F., \& Kalish, D. (1946a). Studies in spatial learning: I. Orientation and the short-cut. Journal of Experimental Psychology, 36, 13-25.

Tolman, E. C., Ritchie, B. F., \& Kalish, D. (1946b). Studies in spatial learning: II. Place learning versus response learning. Journal of Experimental Psychology, 36, 221-229.

Vidal-Gonzalez, I., VIDAL-Gonzalez, B., Rauch, S. L., \& QUiRK, G. J. (2006). Microstimulation reveals opposing influences of prelimbic and infralimbic cortex on the expression of conditioned fear. Learning \& Memory, 13, 728-733.

Wagner, A. R., Thomas, E., \& Norton, T. (1967). Conditioning with electrical stimulation of the motor cortex: Evidence of a possible source of motivation. Journal of Comparative \& Physiological Psychology, 64, 191-199.

WARD-Robinson, J., \& Hall, G. (1996). Backward sensory preconditioning. Journal of Experimental Psychology: Animal Behavior Processes, 22, 395-404.

YAmamoto, T. (2007). Brain regions responsible for the expression of conditioned taste aversion in rats. Chemical Senses, 32, 105-109.

ZENER, K. (1937). The significance of behavior accompanying conditioned salivary secretion for theories of the conditioned response. American Journal of Psychology, 50, 384-403.

ZENER, K., \& MCCURDY, H. G. (1939). Analysis of motivational factions in conditioned behavior: I. The differential effect of changes in hunger on conditioned, unconditioned, and spontaneous salivary secretion. Journal of Psychology, 8, 321-350.

(Manuscript received April 1, 2008; revision accepted for publication April 18, 2008.) 